\title{
EMBRYONIC DEVELOPMENT OF GLIAL CELLS AND THEIR JUNCTIONS IN THE LOCUST CENTRAL NERVOUS SYSTEM ${ }^{1}$
}

\author{
LESLEY S. SWALES AND NANCY J. LANE \\ The A.F.R.C. Unit of Insect Neurophysiology and Pharmacology, Department of Zoology, University of Cambridge, \\ Cambridge CB2 3EJ, United Kingdom
}

Received February 14, 1984; Revised June 6, 1984; Accepted July 23, 1984

\begin{abstract}
The embryonic development of the specialized glial cells that form the perineurial blood-brain barrier in the locust CNS has been studied by freeze-fracture and tracer uptake. These cells migrate to form bracelet cell arrangements around the nervous tissues between day 4 to day 10 of embryonic differentiation which lasts 14 days in toto. A number of different kinds of intercellular junction form between the bracelet cells from day 8 to day 13 of development. These include gap junctions with features characteristic of arthropods, which seem to assemble by lateral migration of 13-nm E face intramembranous particles (IMPs), which ultimately cluster to form a large number of mature plaques of varying diameters. Less numerous are tight junctions which serve to restrict entry of exogenous molecules, including lanthanum and cationic ferritin, thereby forming the bloodbrain barrier; these appear to assemble by migration of individual 8- to 10-nm $\mathbf{P}$ face IMPs into ridges which are found between the overlapping fingers of the perineurial bracelet cell processes. Septate junctions also mature at this stage in embryonic development by apparent assembly of IMPs into characteristic aligned rows; these may serve to slow down the entry of positively charged molecules as well as being adhesive, although anionic ferritin may leak into the CNS even after septate and tight junction formation. The observed changes in cellular associations and the formation of the blood-brain barrier coincide with the onset of mature neuronal electrical properties and spontaneous synaptic input.
\end{abstract}

A number of studies have been made on the CNS of adult arthropods relating to the features of glial cells that ensheath the neurones, and other specialized glia, the perineurial cells, that are restricted to the periphery of the CNS where they form the basis of the blood-brain barrier (see Lane, 1981a). Perineurial glial cells are associated, on their lateral borders, by septate, tight, and gap junctions in insects (Lane and Treherne, 1972; Lane, 1974; Lane et al., 1977) and by tight and gap junctions in arachnids (Lane and Chandler, 1980; Lane et al., 1981; Lane, 1981b), while tight junctions are absent in tick CNS (Binnington and Lane, 1980) and that of primitive chelicerates (Harrison and Lane, 1981). From these studies, it seems that the interglial tight junctions, when present, serve to form the morphological basis of a blood-brain barrier (Lane, 1981c) while gap junctions permit coupling between adjacent glial cells. Septate junctions appear to act as adhesive devices. Investigations into the assembly of some of these junctional complexes, during embryonic and pupal development, notably of the gap and tight junctions between glial cells, have been made on the CNS of holometabolous insects such as the dipteran blow fly Calliphora (Lane and Swales, 1978a, 1978b) and the lepidopteran moth Manduca (Lane and Swales, 1979, 1980) as well as

\footnotetext{
${ }^{1}$ We are very grateful to Mr. William M. Lee for preparing the photographic montages, and to Mrs. Vanessa C. Rule for typing the manuscript.
}

on the nervous systems of arachnids such as the spider Tegenaria (Lane, 1981b). Examinations of the stages that occur during the differentiation and assembly of septate junctions have been carried out on the CNS and gut in embryos of the blow-fly, locust, and moth (Lane and Swales, 1978a, 1978b, $1982 \mathrm{~b})$. However, a detailed account of the manner in which the perineurial cells themselves become associated and aligned during embryogenesis to establish the blood-brain barrier has not yet been made, nor have studies been made on the embryonic assembly of gap and tight junctions in hemimetabolous insects. We have carried out a series of experiments on the formative stages in perineurial cell maturation during embryonic development of the ventral nerve cord in both the locust and cockroach (Insecta; Dictyoptera), and in this report we describe the process in the former. Certain unusual features in the latter are considered elsewhere (L. S. Swales and N. J. Lane, in preparation). The noteworthy feature of perineurial development reported here is the remarkable lateral extension and overlapping of only a few bracelet cells in this cell layer, which, by the assembly of septate, gap, and tight junctions between their lateral borders, become differentiated to form the occluding blood-brain barrier around the whole circumference of the developing CNS. This paper reports the details of the separation of the differentiating nerve cord from the body wall during neurogenesis in the locust, and follows the temporal sequence of events leading to the formation of the perineurial barrier around the mature hatchling CNS. 


\section{Materials and Methods}

The embryos used in these experiments were of the locust, Scistocerca gregaria, maintained in moist sand in the laboratory at $28^{\circ} \mathrm{C}$; under these conditions, the eggs took 14 days after laying to differentiate and proceed to the hatchling stage. Embryos were removed from egg cases for examination at intervals from day 4 through day 14 as well as after hatching. In the early stages the embryos, having been carefully dissected out, were opened by a lateral incision to reveal the developing ventral nerve cord, and incubation or fixation was carried out on the whole nerve cord in situ. In later stages, when the nerve cord was larger, it was possible to dissect it out, which was particularly useful for freeze-fracturing. The developing nerve cords were fixed and embedded for conventional thin sections at a variety of stages or were fixed and then washed and cryoprotected before being frozen for freezecleaving. To assess the stage of formation of the blood-brain barrier, some nerve cords at every stage were incubated for varying periods of time in solutions of ionic lanthanum, cationic ferritin, or anionic ferritin, made up in locust Ringer, to determine the extent of tracer penetration; after such treatment the nerve cords were fixed, dehydrated, and Araldite-embedded.

Fixation. Ventral nerve cords were taken at 1-day intervals from embryos of 4-day duration through day 14 from hatchlings, and for some experiments, from adults. Dissections were carried out in locust Ringer, the composition of which was as follows; glucose $90 \mathrm{mM} ; \mathrm{NaCl}$, $140 \mathrm{mM}$; KCl, $8.25 \mathrm{~mm}$; KOH, $1.75 \mathrm{~mm}$; Hepes, $5 \mathrm{mM}$; $\mathrm{CaCl}_{2}, 2 \mathrm{mM}$; totaling 401 mosm. Glucose was added to bring the osmolarity of the Ringer closer to that of the hemolymph which is $452 \mathrm{mosm}$. The tissues were fixed for $1 \mathrm{hr}$ at room temperature in $2.5 \%$ glutaraldehyde in 0.05 M phosphate buffer, $\mathrm{pH} 7.4$, plus $6 \%$ sucrose, followed by three washes in phosphate buffer plus $6 \%$ sucrose. The tissues were then stained with $1 \%$ osmium tetroxide $\left(\mathrm{OsO}_{4}\right)$ in phosphate buffer plus $6 \%$ sucrose for $1 \mathrm{hr}$ at room temperature. Further buffer washing and en bloc staining with aqueous uranyl acetate was followed by dehydration through an ascending series of ethanols to propylene oxide and embedding in Araldite. Thick sections were stained with toluidine blue-borax and examined in a light microscope. At all stages, the ultrathin sections were cut through the third thoracic ganglion at right angles to the longitudinal axis of the ventral nerve cord, just above the point of emergence of the abdominal interganglionic connectives. These were stained with uranyl acetate and lead citrate before being examined in a Philips EM 300 at 60 or $80 \mathrm{kV}$.

Lanthanum incubation. Ventral nerve cords were taken from the same embryonic stages as were examined for conventional fixation. To ensure adequate exposure of the nerve cord to the tracer, samples were treated in one of several ways. These included (1) whole eggs incubated after the anterior pole had been cut; (2) embryos removed from the egg case and incubated intact; (3) embryos removed from the egg case and a dorsal cut made to remove part of the body wall to expose the ventral nerve cord to the tracer; or (4) in hatchlings and adults, dorsal dissection to expose the nerve cord, followed by incubation in situ.

Samples were incubated in $10 \mathrm{mM}$ ionic lanthanum (prepared from lanthanum chloride) in locust Ringer for $1 \mathrm{hr}$ at room temperature. Lanthanum in physiological saline was used rather than adding the tracer to the fixative as is commonly done, in order to ensure that the uptake of the tracer would occur as in vivo. Control tissues were incubated in saline but without added lanthanum. Following incubation, the tracer solution was replaced with fixative, $2.5 \%$ glutaraldehyde in $0.05 \mathrm{M}$ phosphate buffer, pH 7.4, plus $6 \%$ sucrose. After 10 to 20 min, the nerve cords of adults, hatchlings, and embryos over 10 days old were dissected out and placed in fresh fixative. Samples were fixed for a total of $\mathrm{l} \mathrm{hr}$ and then dehydrated and embedded as described above.

Cationic and anionic ferritin. In these experiments, the ventral nerve cords of 8-day, 10-day, and 13-day embryos, hatchlings, and adults were investigated. These tissues were dissected in locust Ringer with added glucose for incubation in three different ways: (1) embryos were removed from the egg case and incubated intact; (2) embryos were removed from the egg case and a dorsal cut was made; or (3) the ventral nerve cord was dissected out.

The tissue was incubated in $10 \mathrm{mg} / \mathrm{ml}$ cationized ferritin in $0.15 \mathrm{M}$ $\mathrm{NaCl}$ (horse spleen ferritin coupled with $N, N$-dimethyl-1,3-propanediamine from Sigma) or $110 \mathrm{mg} / \mathrm{ml}$ anionic ferritin $(2 \times$ crystallized, $\mathrm{Cd}$-free, in $0.15 \mathrm{M} \mathrm{NaCl}$ solution from Polysciences) for $30 \mathrm{~min}$ or as long as $24 \mathrm{hr}$ at room temperature; controls were incubated in Ringer. The tissue was then transferred to $2.5 \%$ glutaraldehyde in $0.05 \mathrm{M}$ phosphate buffer, $\mathrm{pH} 7.2$, plus $6 \%$ sucrose for $1 \mathrm{hr}$ at room temperature. Several changes of fixative werc made to remove the excess ferritin that leaks out during fixation. No further dissection of the tissue took place and it was then washed and treated as described above for conventional fixation and embedding.

Freeze-fracturing. Freeze-fracturing studies were only made at stages in embryonic development after day 8; at this and subsequent stages, the nerve cord could be dissected out intact while in the earlier stages this was impossible owing to its not having formed as a separate organ and being intimately attached to the body wall. The nerve cord tissue was fixed for $30 \mathrm{~min}$ at room temperature in $2.5 \%$ glutaraldehyde in $0.05 \mathrm{M}$ phosphate buffer, $\mathrm{pH} 7.2$, plus $6 \%$ sucrose, washed in phosphatebuffered sucrose several times, followed by cryoprotection with $20 \%$ glycerol in phosphate-buffered sucrose for $30 \mathrm{~min}$. In some experiments, unfixed tissue was examined; in these cases the glycerol was made up in locust Ringer. The tissue was then mounted in yeast in copper holders and frozen in liquid Freon 22 cooled by liquid nitrogen. Replicas were prepared using a Balzers (BA $360 \mathrm{M}$ ) freeze-fracturing device at $-100^{\circ} \mathrm{C}$ with a pressure of $2 \times 10^{-6}$ torr $(1$ torr $=133.3 \mathrm{~Pa})$ followed by shadowing with tungsten-tantalum and backing with carbon. After admission of air, while still on the cold table of the fracturing unit, the replicas were coated with a drop of celloidin. Holders were removed from the device and the celloidin was allowed to dry before the replicas and tissue were removed from the holders and cleaned as intact replicas with sodium hypochlorite. The celloidin was removed by submerging the mounted replicas in amyl acetate. The cleaned replicas were then examined in a Philips FM 300 at 60 or $80 \mathrm{kV}$.

\section{Results}

Perineurial cell development. In the early embryos, day 4 was the stage at which the neuropile was first recognizable, in the form of very tiny cellular processes, surrounded by the more peripheral nerve cell bodies. Stages in the glial cell ensheathment of the neuropile (Fig. 2) were followed through to hatching, which usually occurred by day 14; by this stage, the perineurial cells formed two layers in the ganglia, an outer layer and an inner bracelet cell layer (Fig. 1).

The perineurial cells, which are at first in the form of large cells only, by day 4 or 5 can be seen to line up against a thin layer of matrix material, which looks like a thin basement membrane, lacking collagen (Fig. 3). It seems that this extracellular matrix material has been laid down earlier in embryogenesis, and serves to determine the orientation of these "bracelet" cells. The latter are so-called because each cell ultimately becomes very extensive laterally and a very few such cells are able, by overlapping their lateral processes, to form a bracelet, encompassing the entire diameter of the developing nerve cord. An cxtraccllular neural lamella is produced in later stages which makes more substantial the wispy matrix material already present; this neural lamella appears to be synthesized by the perineurial cells. Smaller glial cells at later stages come to insinuate themselves above the bracelet cells. These smaller perineurial cells are more common in ganglia than in interganglionic connectives; the latter tend to have a perineurium comprised of bracelet cells only.

After 6 to 7 days of development, glial cells and axons are loosely associated (Fig. 2) in the center of the developing CNS and the perineurium has also begun to develop on the side of the neuropile opposite the body wall by the amnion folds (Fig. 3 ). Between the body wall with its developing hypodermis and the clustered glial processes and axons lie neuroblast cells; these occasionally exhibit short gap junctions with one another. By day 8 or 9 , axonal and glial processes can be distinguished in the developing neuropile since the latter by then not only tend to be thinner but also exhibit a greater electron opacity than do the axons (Figs. 4 and 5).

By day 10 , the bracelet cells have formed a complete circle around the developing nerve cell bodies and neuropile and have insinuated themselves between the CNS and the body wall (Fig. 4). As stressed earlier, because they are so extensive, only a relatively few cells are required to completely surround the 

through a ganglion of the ventral nerve cord to illustrate the arrangement of the outer perineurial cells (densely stippled) and the underlying perineurial bracelet locust. The enlargement at the top shows $(S J)$, gap junctions $(G J)$, and tight junctions $(T J)$ between bracelet cell processes.
Figure 1. Diagram of a cross section cells around the developing CNS in the the distribution of septate junctions
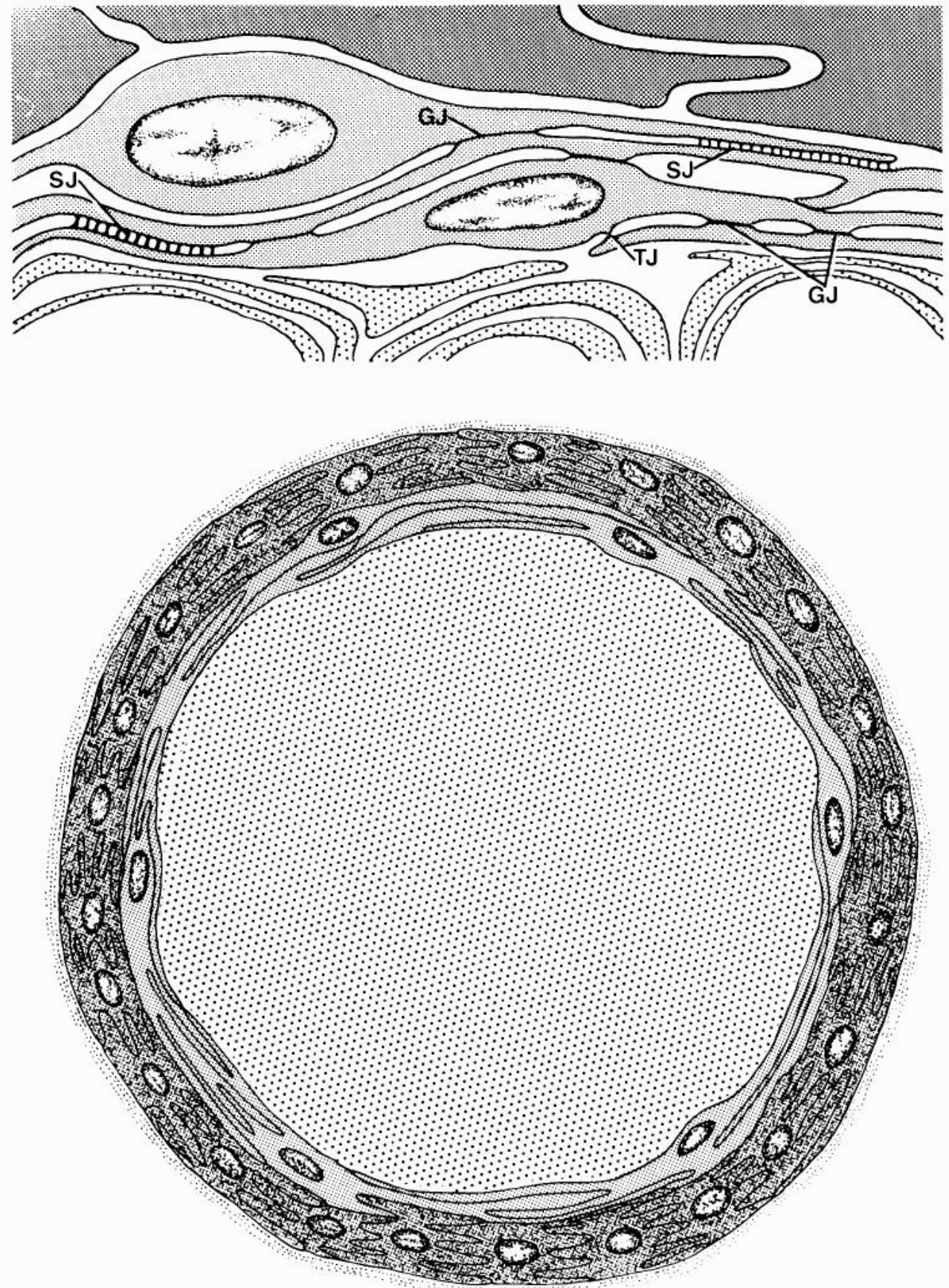

CNS. Bracelet cell projections may invaginate deep into the underlying region of axons or nerve cell bodies and these processes may also surround the nerve cells or axons, thereby acting as conventional glial cell projections (Fig. 4). The overlapping surfaces of the bracelet cell processes are associated by many gap junctions (Fig. 6) and septate junctions (Figs. 8 to 14 and 16) (see "Features of the Intercellular Junctions in FreezeFracture Replicas"). In some cases, cytoplasmic cross-bridges are seen between branches of the same cell. A ring of tight junctions, featuring punctate cell-cell appositions, forms near the end of the "fingers" of the bracelet cell processes (Figs. 12 and 13 , inset); these have developed by day 13 and seem to act as the final seal to the blood-brain barrier. The bracelet cells, with their associated junctions, are illustrated diagrammatically in Figure 1.
Lanthanum entry followed by exclusion. In lanthanum-incubated preparations, from as early as day 4 and seen here at day 7 , the developing neuropile is identifiable and is completely accessible to this ionic tracer (Fig. 2). At this stage, the hypodermis lies on the external side of the developing nerve mass and the amnion folds lie on the side facing the internal environment. The bracelet cells have begun to move around the nervous tissue (Fig. 3) but the system is still "leaky" at day 6 . By days 8 to 9 , the septate junctions have begun to form between these cells and lanthanum infiltration reveals their ribbon-like septa (as in Fig. 10). Although the bracelet cells are nearing their final arrangement at day 10, some traces of lanthanum are still leaking through; in certain regions even at day 13 , the tracer can be seen to have been apparently restricted by a septate junction (Fig. 11). However, in other cases, these 

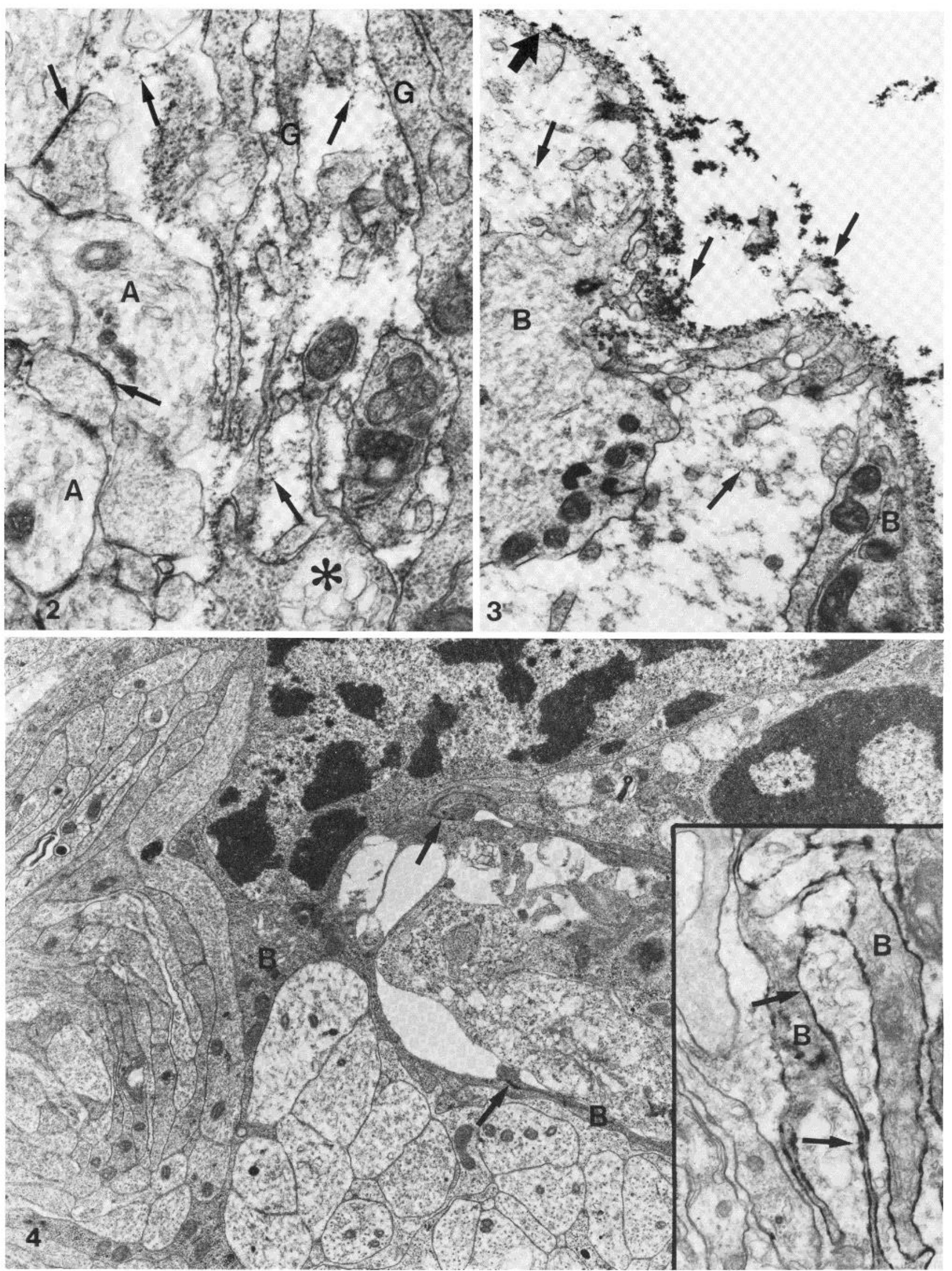

Figure 2. Seven-day embryo incubated in $10 \mathrm{~nm}$ ionic lanthanum, showing the developing CNS with axons $(A)$ and glial cell $(G)$ processes intermingled as they establish their positions and connections. *, vesiculate process, often encountered in these early stages. The lanthanum (arrows) has access throughout the nervous system which has not yet become ensheathed. Magnification $\times 43,000$.

Figure 3. Six-day embryo of locust showing the outer surface of the CNS where the bracelet cells $(B)$ of the perineurium are becoming aligned under the wispy matrix of basal lamina (large arrow). Note that the lanthanum (arrows) has access to the extracellular space so that there is no restriction as yet to tracer entry. Magnification $\times 23,500$.

Figure 4. Thirteen-day embryo showing the CNS in a greater state of order than earlier with the extracellular space much reduced. The bracelet cell $(B)$ shown here has projections which have invaginated deep into the nervous tissue, wrapping around the axons and acting as conventional glial cells. Lanthanum does not at this stage penetrate into the body of the CNS except where it follows these bracelet cell processes inwards (at arrows) (shown in inset). Magnification $\times 17,000$; inset, $\times 26,000$. 

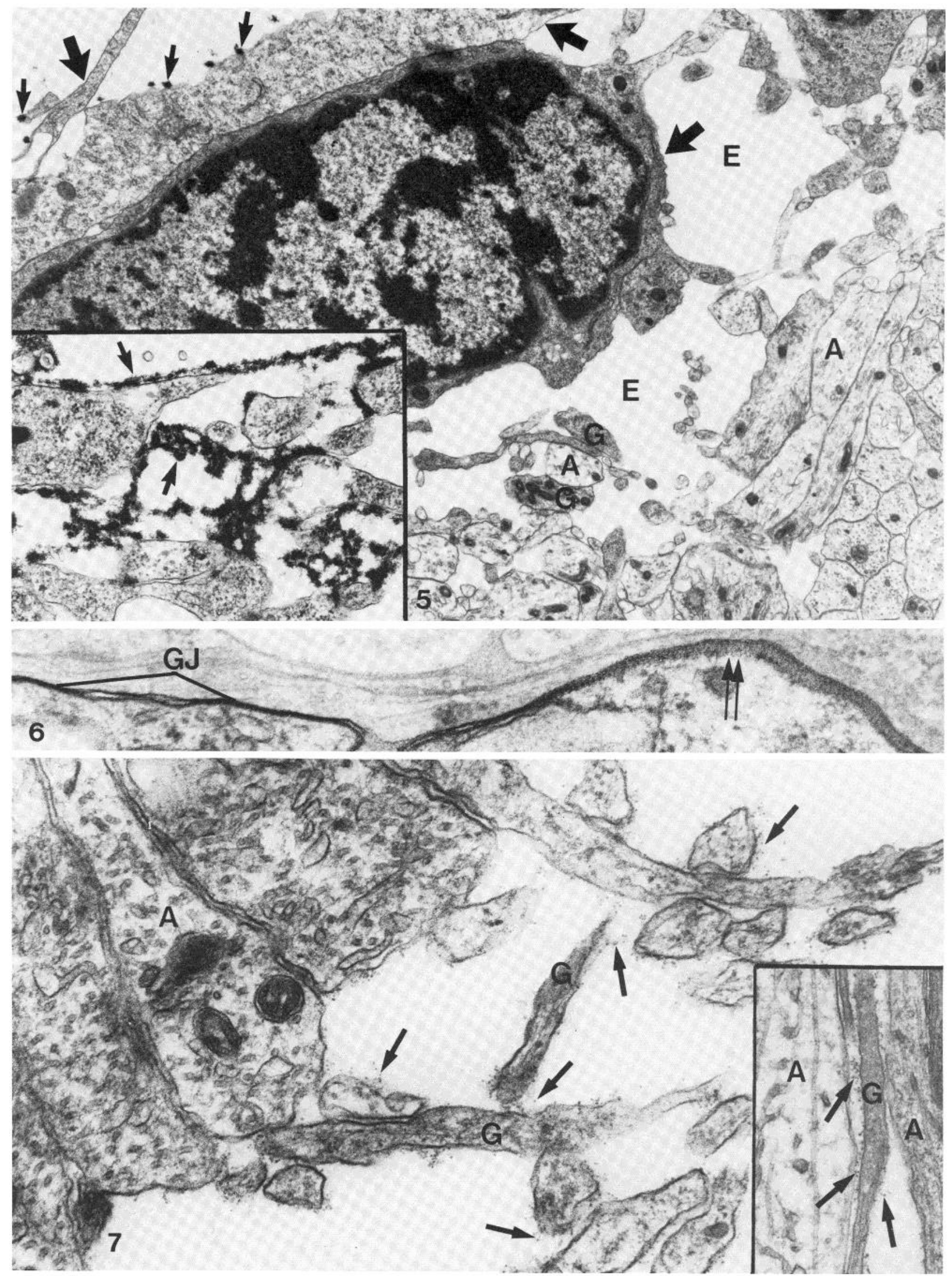

Figure 5. Developing CNS from a 10-day embryo incubated in cationic ferritin (at arrows); the tracer can be seen to be restricted to the regions of the overlapping bracelet cells (large arrows). Their peripheral junctions prevent the ferritin from entering the CNS, even though the glia $(G)$ and axons $(A)$ are still in the process of differentiating with extensive extracellular space $(E)$. The glial cells look more electron opaque than the axons by this stage. Inset shows cationic ferritin over regions between perineurial cells, adhering to the matrix to which it binds in clusters (arrows) rather than producing a diffuse label all through the extracellular space. Magnification $\times 12,000 ;$ inset, $\times 26,000$.

Figure 6. CNS from a hatchling with the perineurial bracelet cells fully formed, incubated in cationic ferritin. Here the gap junctions (GJ) can be seen, in some cases cut en face to reveal the component connexons (arrows). Magnification $\times 77,000$.

Figure 7. Ten-day locust embryo incubated with anionic ferritin (arrows) which has infiltrated the spaces in the developing CNS, where axons $(A)$ and glia $(G)$ are becoming associated. Inset shows a 13-day embryo, just before hatching, with the CNS extracellular space much reduced, but still accessible to anionic ferritin (at arrows). Magnification $\times 66,000$; inset, $\times 46,000$. 


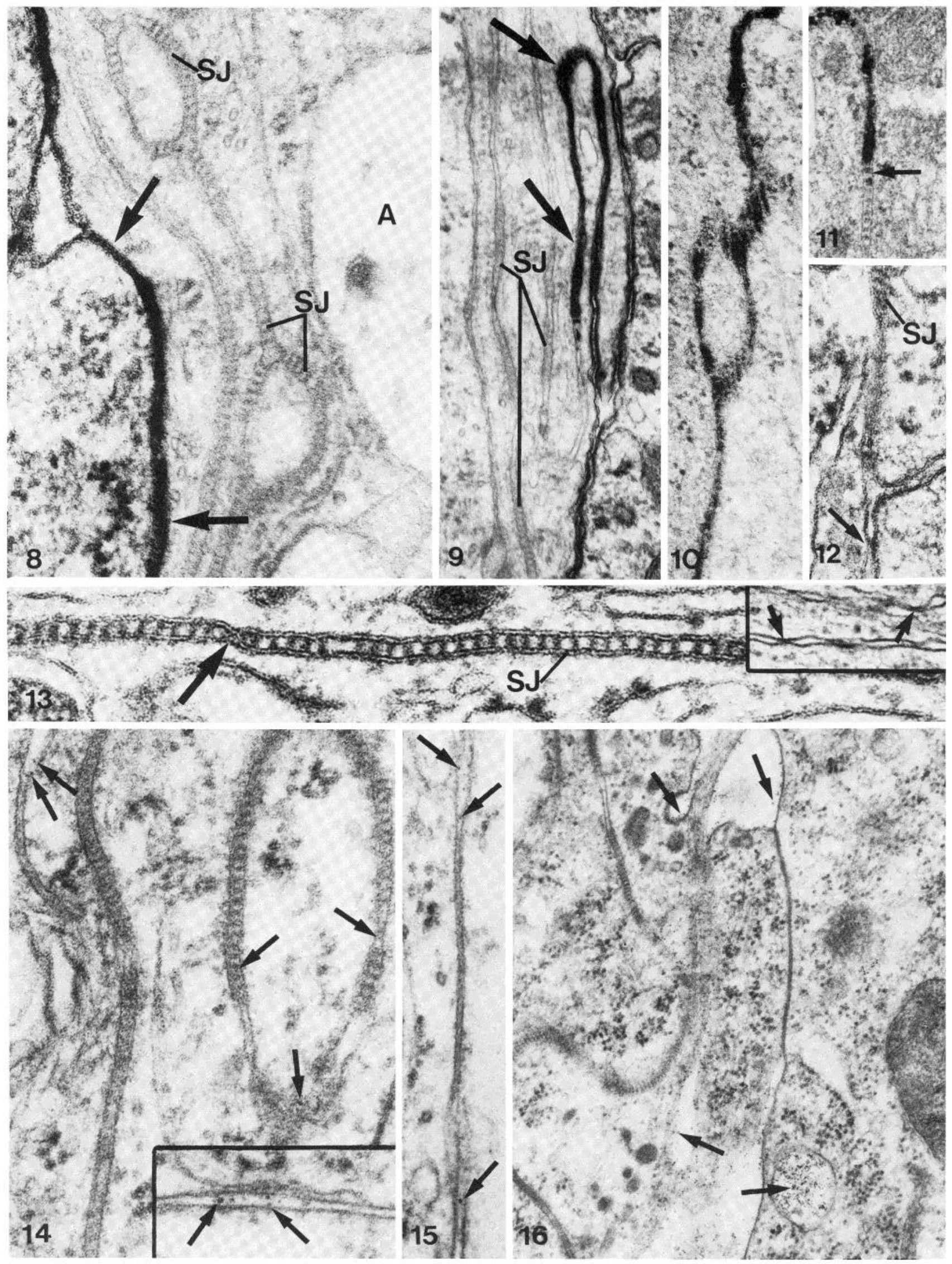

Figures 8 and 9. Hatchling CNS in an area of bracelet cells after incubation with cationic ferritin. The tracer was found in the perineurial clefts $(a r r o w s)$ but not in the underlying septate junctions $(S J)$ or glial-ensheathed axons $(A)$ below. Magnification: Figure $8, \times 105,000$; Figure $9, \times 69,000$.

Figures 10 and 11. Thirteen-day embryo in a region of CNS bracelet cell septate junctions after incubation with $10 \mathrm{~mm}$ ionic lanthanum. In some cases (arrows), the tracer appears to stop in the junction although in others (Fig. 10), it moves through. Magnification: Figure 10, $\times 74,000$; Figure 11, $\times 91,000$. 
junctions are completely full of tracer and are found above the level of the barrier (Fig. 10). By day 13, the tight junctions have formed, the barrier is complete, and no traces of lanthanum can be found in the neuropile region, even after $24-\mathrm{hr}$ incubation. The intercellular clefts in the outer regions of the perineurium are infiltrated with lanthanum whose further entry would seem to be stopped at the base of the perineurium by the tight junctions between the large bracelet cell overlappings; this stage is similar to the situation observed in the adult. When the perineurial cell processes invaginate down into the nervous tissue, acting as conventional glial cells (Fig. 4), tracer can sometimes follow them (inset to Fig. 4), producing localized areas with lanthanum in the interglial clefts. However, the tracer is never found beyond these spaces.

Cationic and anionic ferritin uptake. At days 8 to 10 , the perineurium is accessible to the entry of ferritin as this tracer can be found throughout the developing system (Fig. 7) after incubation for $30 \mathrm{~min}$. By day 10, the entry of cationic ferritin is precluded (Fig. 5 and inset) and, although it moves through gap junctions (Fig. 6), in some cases it seems to stop in septate junctions (Fig. 9). At day 10, quantities of anionic ferritin still infiltrate the spaces between axons and glia (Fig. 7). By day 13, just before hatching, and at later stages, anionic ferritin, which leaks through the septate junctions (Fig. 14) and past gap junctions (Fig. 15), can still be seen to be capable of making its way through the perineurial junctions and below to the glialaxonal spaces since a few molecules may be found there (inset to Fig. 7). Cationic ferritin, however, does not penetrate beyond the perineurial barrier at this stage (Fig. 8), even after 24-hr incubation. Hence, a finite leak to anions seems likely, as has been reported earlier electrophysiologically (Pichon et al., 1971). Anionic ferritin is also taken up by perineurial cells by exocytosis (arrows in Fig. 16).

Features of the intercellular junctions in freeze-fracture replicas. As mentioned earlier, the perineurial bracelet cell processes are ultimately associated by gap junctions, septate junctions, and tight junctions. The gap junctions are characterized in late embryos by relatively closely packed plaques of $13 \mathrm{~nm}$ E face particles (Fig. 17). In earlier stages, from day 9 or earlier (Fig. 20), dispersed or very loosely associated intramembranous particles (IMPs) of similar size and fracturing characteristics are found spread over presumptive junctional membrane faces. These would appear to represent gap junctions in the process of assembly with the individual IMPs in loose linear arrays (Fig. 20) apparently coalescing into the mature plaques (inset, Fig. 20); several of these apparent stages in formation may appear on the same membrane face and, in embryos at the same age, a range of stages may be found. When assembled, these gap junctions may be very extensive indeed (Fig. 17) or quite small (Fig. 18) in surface area. Not only do they occur as homocellular interactions between the lateral borders of homologous cells but they may also be found as autocellular junctions, between cytoplasmic processes of the same cell. Heterocellular junctions are occasionally found between processes of a bracelet cell with an underlying glial cell. The majority of the gap junctions associated with the perineurium are found above or at the level of the barrier so that they frequently become infiltrated with tracer (Fig. 6).

Mature gap junctions between bracelet cells in late embryonic stages may consist of plaques of either closely packed IMPs or connexons (Fig. 18) or ones that are in clusters, but more loosely aggregated (Fig. 19); both kinds may be on the same membrane face (Fig. 18) or, indeed, even within the same junction (inset to Fig. 18). This may reflect differences in the state of coupling of fully formed junctions. The diameter of these connexons is the same $(13 \mathrm{~nm})$ in both clustered and nonclustered junctions.

Pleated septate junctions in mature embryos feature parallel alignments of IMP rows lying on the membrane $P$ face. The IMPs are 8 to $10 \mathrm{~nm}$ in diameter and are clearly separated from one another with complementary pits in the $\mathrm{E}$ face which often appear as EG grooves (Fig. 20). In early embryos, developing perineurial cells feature scattered PF IMPs, followed by situations in which IMPs become aligned with one another, in rows, which appear to "meander" laterally over the presumptive septate junctional surface as if to establish their pattern and territory. This process has been described in detail earlier (Lane and Swales, 1982b). Septate junction development occurs very rapidly so that although they are not present on day 7 they appear fully formed by day 10 (Figs. 8 to 14). They may often be found in intimate spatial association with gap junctions (Fig. 20) or tight junctions (Figs. 12 and 13).

What seem to be the freeze-fracture correlate of the punctate tight junctional appositions seen in thin sections, are 8 to 10 nm IMPs which appear as PF ridges due to their close packing side by side (Fig. 22). 'T'hese tight junctional bands are restricted in distribution and are found around the rather small perineurial bracelet cell processes; they are first seen as short rods at day 8 (Fig. 21) which seem to become aligned (Fig. 22) and appear completely fused into longer ridges by day 13 (inset, Fig. 22). These, therefore, appear to become assembled by individual IMPs becoming organized into linear arrays (Figs. 21 and 23). Since they are restricted to the ends of the bracelet cell fingers, they are relatively scarce and PF/EF fracture face transitions have not been found as they have in insect tissues more richly endowed with tight junctions (Lane, 1981a, 1981b, 1981c). Less extensive tight junction ridges may be found in the more peripheral regions parallel to the periphery and the forming neural lamella. Although these could not form the final barrier, they may help slow down the entry of exogenous molecules by restricting the width of the intercellular clefts.

\section{Discussion}

This study shows that the perineurial cells of the locust CNS come to surround the developing neuroblast cells and their ensheathing glial cells during the last half of the 14-day period of embryonic development. It is clear that the bracelet cells and their junctions are that component of the perineurium which is crucial in forming the morphological basis of the bloodbrain barrier. That the perineurium is responsible for producing this barrier in insects is relatively long established (Lane and Treherne, 1970, 1972; Lane, 1974, 1978, 1981c; Lane et al., 1977) and bracelet cells have been particularly implicated (McLaughlin, 1974) in the metamorphosing moth Manduca sexta. In the locust, it is clear that the bracelet cells are also the crucial element since in the interganglionic connectives of hatchlings and adults, bracelet cells only are present and the perineurium is, in consequence, exceedingly attenuated. In the ganglia, however, after hatching, in addition to the bracelet cells, other cells also contribute to the perineurium, making it thicker and more substantial.

Figures 12 and 13. CNS from 13-day embryo at which stage the bracelet cell processes are associated by septate junctions (SJ) and tight junctions (arrows). Magnification: Figure 12, $\times 130,000$; Figure 13, $\times 211,000$. Inset, showing punctate tight junctions, $\times 95,000$

Figures 14 to 16. Hatchling CNS incubated with anionic ferritin which appears to be present in the septate junctions (arrows) in Fig. 14), the regions beside a gap junction (arrows in Fig. 15), in the extracellular space (arrows in Fig. 14, inset), and in endocytotic vesicles (Fig. 16). Magnification: Figure 14, × 97,000; Figure 15, × 98,000; Figure 16, 43,500. Inset, Figure 14, × 118,000. 


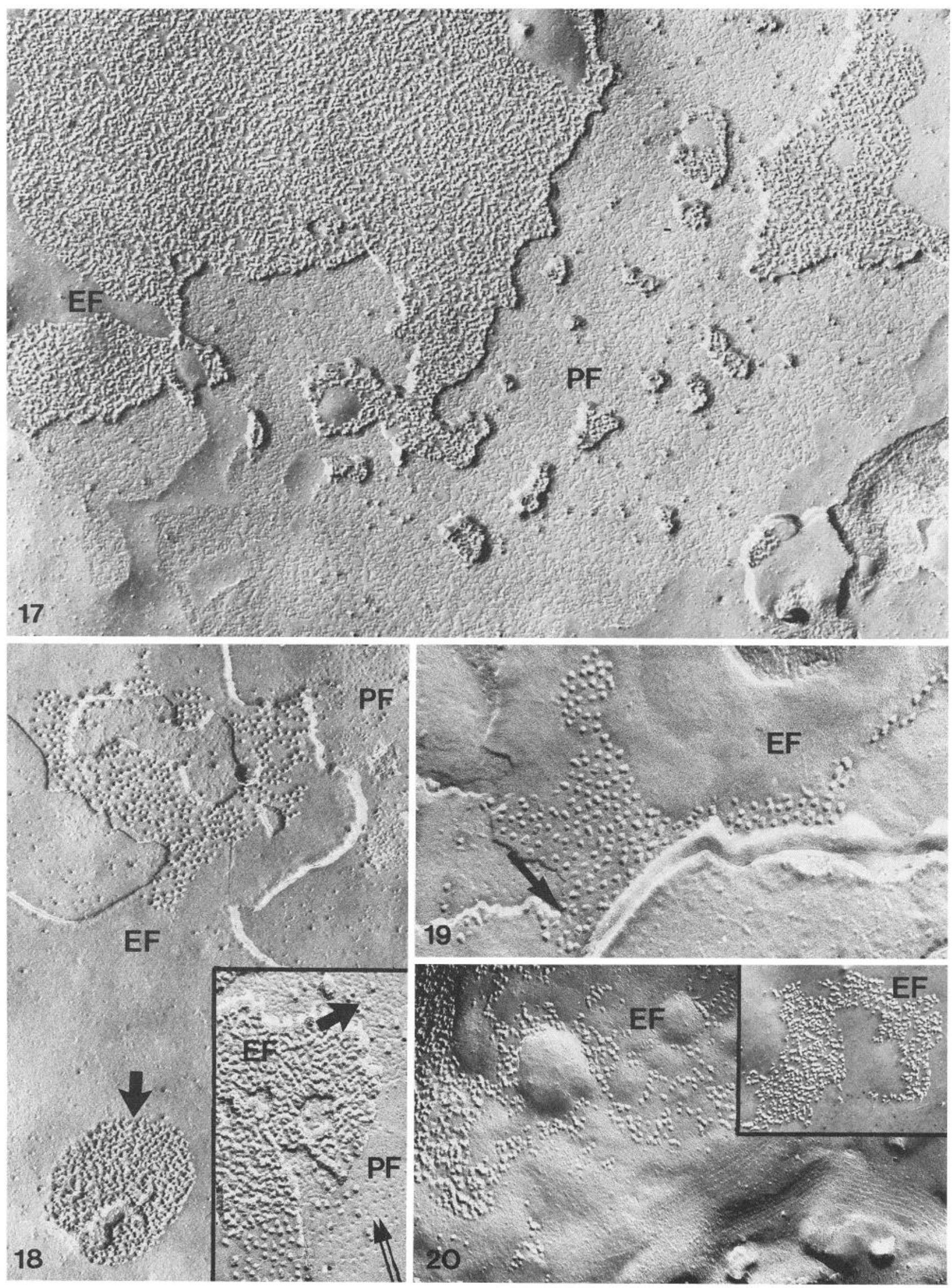

Figures 17 to 20. Freeze-fracture replicas of gap junctions from the bracelet cells of the developing CNS in 9-day (Figs. 18 and 20), 10-day (Fig. 19), and 11-day (Fig. 17) embryos. The gap junctions appear to assemble by translateral migration of the scattered $E$ face (EF) connexons (Fig. 20) which gradually aggregate around day 9 or before. The junctions may be extremely large (Fig. 17) and they exhibit variability in clustering. Some connexons are loosely packed (Fig. 19) and may occur on the same membrane face (Fig. 18) or within the same junction (inset, Fig. 18), as do others that are closely packed (large arrow). The $\mathrm{P}$ face $(P F)$ shows the pits complementary to the EF connexons and these too 
During embryogenesis in the locust, the perineurial junctions seal off the developing CNS by producing intercellular occlusions which inhibit the inward movement of exogenous ions and molecules, in this case, ionic lanthanum and cationic ferritin; this restriction occurs at about day 12 , more than three-fourths of the way through embryonic development. In close correlation with this, the onset of electrical excitability of neurones in a comparable system, the developing grasshopper CNS (Goodman and Spitzer, 1979), takes place about threefifths of the way through embryogenesis with mature electrical properties being established just afterwards (Goodman and Spitzer, 1981). The sensitivity of the neurones in the grasshopper, to bath application or iontophoresis of acetylcholine or GABA, occurs between two- and three-fifths of the way through CNS development but spontaneous synaptic activity is not observed until three-fourths of the way through (Goodman and Spitzer, 1980); the same has been shown to be true for developing cockroach CNS (J. Blagburn, D. Beadle, and D. B. Sattelle, manuscript in preparation). Insect neurones may be unable to function effectively until they are protected from fluctuations in the circulating hemolymph by a perineurial barrier. However, before the perineurial tight junctions form to establish the blood-brain barrier, the ion levels in the hemolymph of insect embryos may be more favorable for neuronal conduction than the levels in the adult, for preliminary obser- vations indicate that in locust embryos, at day 11 , the $\mathrm{K}^{+}$level is less than in the adult, while the $\mathrm{Na}^{+}$level appears higher (P. K. Schofield, unpublished observations). This would reduce the need in the embryo for active regulation of the neuronal environment by ionic mechanisms as occurs in adult insects (Treherne and Schofield, 1979, 1981).

The loss of the electrical coupling observed between neuroblast cells in developing grasshopper CNS (Goodman and Spitzer, 1979) occurs just before the time that the axonal processes and their glial ensheathments are beginning to assume a mature configuration in locust CNS. This in turn coincides with a reduction in the intercellular spaces that are so prominent in the early stages when the cells are migrating to take up their final positions; it also can be correlated with glial ensheathment of the nerve cell bodies which would inhibit both perikaryal synaptic input and coupling.

The extracellular matrix strands of the basement membrane against which the perineurial cells come to lie have been reported to exist in early stages of developing CNS of other insects such as the grasshopper (Bate and Grunewald, 1981); there it is considered to represent the cue to which the first growing axons respond, permitting a transfer of pattern from the neuro-ectodermal cell sheet. Some comparable phenomenon may be occurring here. The origin of this matrix is, however, as yet unclear.
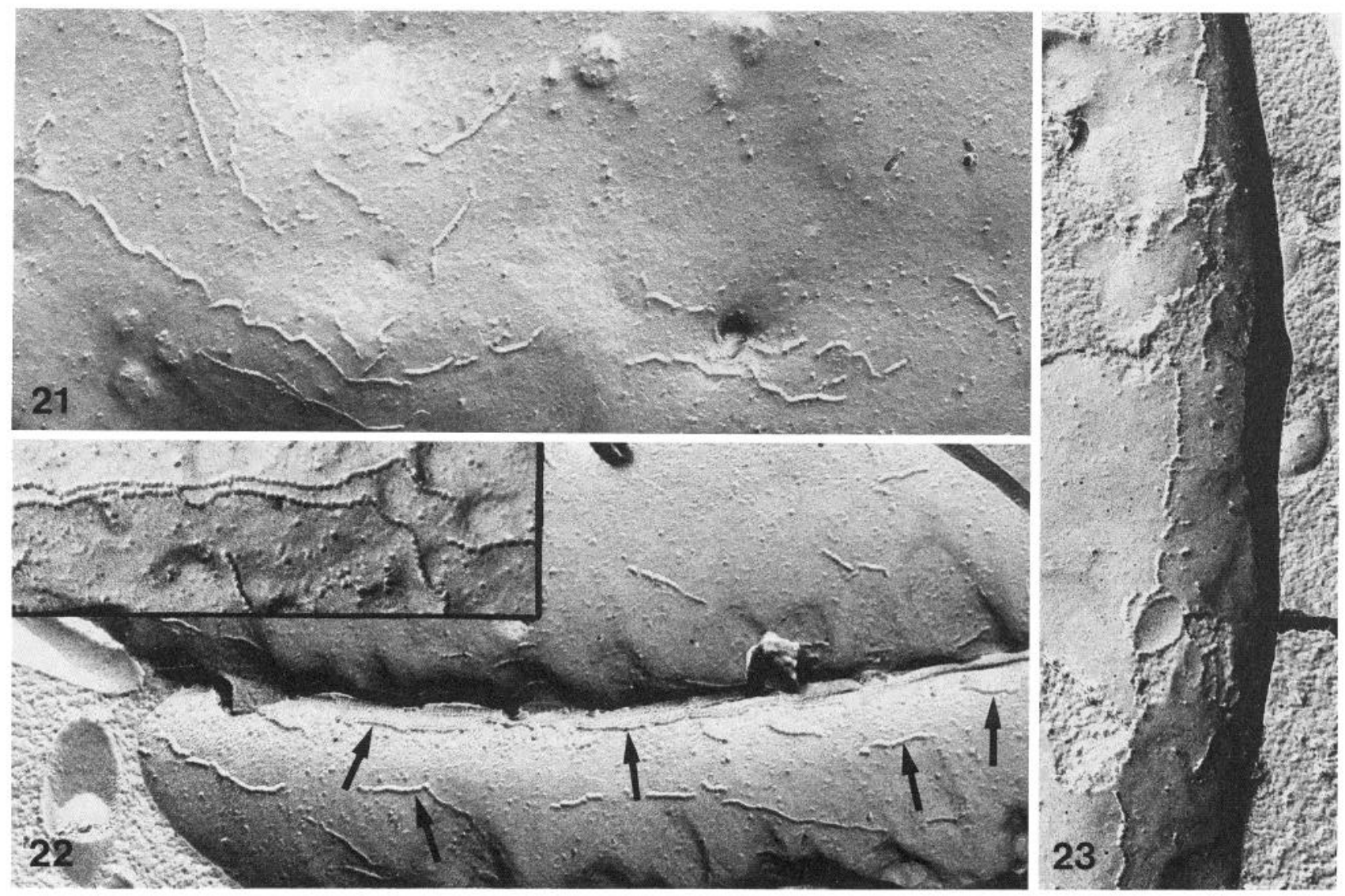

Figures 21 to 23. Freeze-fracture replicas of CNS bracelet cell tight junctions in various stages of assembly, from 8-day (Fig. 21), 10-day (Figs. 22 and 23) to 13-day (inset, Fig. 22) embryos showing the alignment of IMPs into short rows (arrows) and then more extensive ridges. Magnification: Figure 21, $\times 60,500$; Figure 22, × 77,000; Figure 23, $\times 67,000$; inset to Figure 22, $\times 102,000$.

are either tightly (large arrows) or loosely (double arrows) packed (inset in Fig. 18). Note the reduced intercellular cleft (arrow in Fig. 19) at PF/ $\mathrm{EF}$ face transitions. The EF grooves characteristic of pleated septate junctions are commonly found on the same membrane face (bottom of Fig. 20 ) as the gap junctions IMPs. Magnification: Figure 17, $\times$ 45,000; Figure 18, $\times$ 49,000; Figure 19, $\times 89,000$; Figure 20, $\times 55,000$; inset to Figure $18, \times 64,000$; inset to Figure $20, \times 39,000$. 
Initially, the perineurial cells are not organized in order to be able to restrict the passage of tracers, and a leak can be seen up to day 11 or 12 when the tight junctions form between overlapping bracelet cell processes. The septate junctions form before this time, and seem to have some effect in slowing down the entry of positively charged ions such as ionic lanthanum or cationic ferritin. This may be a function of the interseptal matrix as the septal ribbons themselves are likely to be fenestrated or permeable in some way since they have been shown not to restrict the passage of molecules such as sucrose, polyethylene glycol, or inulin, which have $M_{\mathrm{r}}=320$ to 5200 (O'Donnell et al., 1983). Moreover, cationic ferritin in the locust CNS appears to bind to the matrix components. Even when the tight junctions around the bracelet cell fingers are formed, however, anionic ferritin is found to leak into the extracellular spaces, albeit in minute quantities. They may reflect the finite leak to certain anions reported in electrophysiological studies of cockroach ventral nerve cord (Pichon et al., 1971).

The embryonic gap junctions between bracelet cell processes appear to assemble in the same way as has been described for glial cells in developing holometabolous insect CNS (Lane and Swales, 1978a, 1979) and vertebrate neural tissue (Decker and Friend, 1974) whereby, with time, individual 13-nm EF connexons apparently migrate laterally until they cluster together to coalesce into macular plaques. 'That gap junctional connexons are clustered closely together has been suggested to be due to glutaraldehyde fixation (Bennett et al., 1972; Sikerwar and Malhotra, 1981) which, it is thought, induces uncoupling. Gap junctions with connexons in the closely packed state have been correlated, in other situations, with physiological uncoupling (Peracchia and Dulhunty, 1976; Perrachia, 1980). However, in fixed locust glial cells, both closely and loosely packed connexons are to be found on the same membrane face or within the same gap junctional plaque (see Fig. 18). Comparable pleiomorphism has been reported after rapid freezing which involves no glutaraldehyde fixation in both insect tissues (Swales and I ane, 1983; I ane, 1984) and those of other organisms (van Deurs et al., 1982; Raviola et al., 1980; Hanna et al., 1981). It may be that only a certain percentage of the gap junctions are actually permitting the exchange of molecules between adjacent cells at any one time. These data, therefore, do not provide evidence for any clear-cut correlation between the closeness of connexon packing in the gap junctions and the state of coupling between the associated cells. Indeed, the closeness of packing of the connexons may not be of any significance with regard to cell to cell coupling. At least some of the vast numbers of gap junctions found in the perineurium at the level of the barrier in the locust CNS may be presumed, however, to form a region of cell-cell communication; ions and molecules, trophic or regulatory, in the cytoplasm of the bracelet cells could be transported across to the underlying glial cells to achieve integrated glial activity.

The tight junctions apparently form by alignment and fusion of the bracelet cell $P$ face IMPs into extensive ridges, as has been reported before in the holometabolous insects Calliphora and Manduca (Lane and Swales, 1978a, 1979). This would involve lateral mobility of the appropriate tight junctional $P$ face 8 to $10-\mathrm{mm}$ IMPs. Septate junctions also seem to undergo a series of stages in assembly involving $\mathrm{P}$ face IMP migration, as reported carlier for insect CNS (Lane and Swales, 1982b), insect ovarian follicle cells (Huebner and Injeyan, 1981), moth embryo (Baldwin and Hakim, 1981), and regenerating Hydra (Wood and Kuda, 1980), but the final organization, of rows of separated IMPs, is very different from that of tight junctions. The lateral membranes of the bracelet cells clearly exhibit a high degree of organizational capacity since these septate junctions form on the same membrane face as do the tight and gap junctions, in some cases concurrently. The regulatory signals to determine onset of assembly and the factors that lead to the specificity that must be involved here, have not yet been identified. This will require, among other things, isolation and characterization of the junctional components. Data from rapid freezing of arthropod tight junctions suggest that they, like vertebrates (Kachar and Reese, 1981, 1982; Pinto da Silva and Kachar, 1982) may possess a lipid component (Lane and Swales, 1982a; Swales and Lane, 1983; Lane, 1984) while isolation of arthropod gap junctions indicates a major protein component (Finbow et al., 1983; Finbow et al., 1984). Rapid freezing of insect septate junctions (Kachar et al., 1983) as well as their isolation (Green et al., 1983) reveals possible protein and glycoprotein moieties. Labeled antibodies raised to the junctional components may ultimately permit the visualization of their intramembrane particles in replicas during the different stages of junctional assembly in embryogenesis.

\section{References}

Baldwin, K. M., and R. S. Hakim (1981) Freeze-fracture analysis of gap and septate junctions in embryos of a moth. Tissue Cell 13: 691699.

Bate, C. M., and E. B. Grunewald (1981) Embryogenesis of an insect nervous system. II. A second class of neuron precursor cells and the origin of the intersegmental connectives. J. Embryol. Exp. Morphol. 61: $317-330$.

Bennett, M. V. L., M. Spira, and G. D. Pappas (1972) Effects of fixatives on electrotonic junctions between embryonic cells. J. Cell Biol. 55: 17A.

Binnington, K. C., and N. J. Lane (1980) Perineurial and glial cells in the tick Boophilus microplus (Acarina: Ixodidae): freeze-fracture and tracer studies. J. Neurocytol. 9: 343-362.

Decker, R. B., and D. Friend (1974) Assembly of gap junctions during amphibian neurulation. J. Cell Biol. 62: 32-47.

Finbow, M. E., J. Shuttleworth, N. J. Lane, and J. D. Pitts (1983) Gap junctions isolated from arthropod tissues. J. Cell Biol. 97: 80A (Abstr. 307).

Finbow, M. E., T. E. J. Boultjens, N. J. Lane, J. Shuttleworth and J. D. Pitts (1984) Isolation and characterization of arthropod gap junctions. EMBO J. 3: 2271-2278.

Goodman, C. S., and N. C. Spitzer (1979) Embryonic development of identified neurones: differentiation from neuroblast to neurone. $\mathrm{Na}$ ture (Lond.) 280: 208-214.

Goodman, C. S., and N. C. Spitzer (1980) Embryonic development of neurotransmitter receptors in grasshoppers. In Receptors for Neurotransmitters, Hormones and Pheromones in Insects, D. B. Sattelle et al., eds., Elsevier Biomedical Press, Amsterdam.

Goodman, C. S., and N. C. Spitzer (1981) The mature electrical properties of identified neurones in grasshopper embryos. J. Physiol. 313: 369-384.

Green, C. R., C. Noirot-Timothée, and C. Noirot (1983) Isolation and characterization of invertebrate smooth septate junctions. J. Cell Sci. 62 : 351-370.

Hanna, R. B., T. S. Reese, R. L. Ornberg, D. C. Spray, and M. V. L. Bennett (1981) Fresh frozen gap junctions: resolution of structural detail in the coupled and uncoupled states. J. Cell Biol. 91: 125A.

Harrison, J. B., and N. J. Lane (1981) Lack of restriction at the bloodbrain interface in Limulus despite atypical junctional arrangements. J. Neurocytol. 10: 233-250.

Huebner, E., and H. Injeyan (1981) Follicular modulation during oocyte development in an insect: formation and modification of septate and gap junctions. Dev. Biol. 83: 101-113.

Kachar, B., and T. S. Reese (1981) Membrane structure at tight junctions in quick frozen tissue. J. Cell Biol. 91: 123A.

Kachar, B., and T. S. Reese (1982) Evidence for the lipidic nature of tight junction strands. Nature 296: 464-466.

Kachar, B., N. A. Christakis, T. S. Reese, and N. J. Lane (1983) An interpretation of the intramembrane structure of septate junctions based on direct freczing. J. Cell Biol. 97: 80A (Abstr. 306).

Lane, N. J. (1974) The organization of the insect nervous system. In Insect Neurobiology, J. E. Treherne, ed., Frontiers of Biology Series, Vol. 35, pp. 1-71, Elsevier/North-Holland, Amsterdam.

Lane, N. J. (1978) Intercellular junctions and cell contacts in invertebrates. In Electron Microscopy 1978. Vol. 3: State of the Art, Symposium, J. M. Sturgess, ed., Proceedings of the 9th International 
Congress on Electron Microscopy, pp. 673-691, The Imperial Press,

Ltd., Toronto, Canada.

Lane, N. J. (1981a) Invertebrate neuroglia: junctional structure and development. J. Exp. Biol. 95: 7-33.

Lane, N. J. (1981b) Evidence for two separate categories of junctional particle during the concurrent formation of tight and gap junctions. J. Ultrastruct. Res. 77: 54-65.

Lane, N. J. (1981c) Tight junctions in arthropod tissues. Int. Rev. Cytol. 73: 243-318.

Lane, N. J. (1984) Intercellular junctions in the CNS: a comparative survey. Trends Neurosci. 7: 95-99.

Lane, N. J., and H. J. Chandler (1980). Definitive evidence for the existence of tight junctions in invertebrates. J. Cell Biol. 86: 765774.

Lane, N. J., and L. S. Swales (1978a) Changes in the blood-brain barrier of the central nervous system in the blowfly during development, with special reference to the formation and disaggregation of gap and tight junctions. I. Larval development. Dev. Biol. 62: 389414.

Lane, N. J., and L. S. Swales (1978b) Changes in the blood-brain barrier of the central nervous system in the blowfly during development, with special reference to the formation and disaggregation of gap and tight junctions. II. Pupal development and adult flies. Dev. Biol. 62: 415-431.

Lane, N. J., and L. S. Swales (1979) Intercellular junctions and the development of the blood-brain barrier in Manduca sexta. Brain Res. 169: $227-245$.

Lane, N. J., and L. S. Swales (1980) Dispersal of gap junctional particles, not internalization, during in vivo disappearance of gap junctions. Cell 19: 579-586.

Lane, N. J., and L. S. Swales (1982a) Liquid propane rapid jet-freezing of intercellular junctions in insect CNS. J. Cell Biol. 95: 92A.

Lane, N. J., and L. S. Swales (1982b) Stages in the assembly of pleated and smooth septate junctions in developing insect embryos. J. Cell Sci. 56: $245-262$.

Lane, N. J., and J. E. Treherne (1970) Uptake of peroxidase by the cockroach central nervous system. Tissue Cell 2: 413-425.

Lane, N. J. and J. E. Treherne (1972) Studies on perineurial junctional complexes and the sites of uptake of microperoxidase and lanthanum in the cockroach central nervous system. Tissue Cell 4: 427-436.
Lane, N. J., H. leB. Skaer, and L. S. Swales (1977) Intercellular junctions in the central nervous system of insects. J. Cell Sci. 26 . 175-199.

Lane, N. J., J. B. Harrison, and R. F. Bowerman (1981) A vertebratelike blood-brain barrier with intraganglionic blood channels and occluding junctions, in the scorpion. Tissue Cell 13: 557-576.

McLaughlin, B. J. (1974) Fine structural changes in a lepidopteran nervous system during metamorphosis. J. Cell Sci. 14: 369-387.

O'Donnell, M., S. H. P. Maddrell, and B. O. C. Gardiner (1984) Passage of solutes through the walls of the Malpighian tubules of Rhodnius. Evidence for paracellular and transcellular routes. Am. J. Physiol. 246: R759-R769.

Peracchia, C. (1980) Structural correlates of gap junction permeation. Int. Rev. Cytol. 66: 81-146.

Peracchia, C., and A. F. Dulhunty (1976) Low resistance junctions in crayfish. Structural changes with functional uncoupling. J. Cell Biol. 70: 419-439.

Pichon, Y., R. B. Moreton, and J. E. Treherne (1971) A quantitative study of the ionic basis of the extraneuronal potential changes in the central nervous system of the cockroach Periplaneta americana. J. Exp. Biol. 54: 757-777.

Pinto da Silva, P., and B. Kachar (1982) On tight-junction structure. Cell 28: 441-450.

Raviola, E., D. A. Goodenough, and G. Raviola (1980) Structure of rapidly frozen gap junctions. J. Cell Biol. 87: 273-279.

Sikerwar, S., and S. Malhotra (1981) Structural correlates of glutaraldehyde-induced uncoupling in mouse liver gap junctions. Eur. J. Cell Biol. 25: 319-323.

Swales, L. S., and N. J. Lane (1983) Insect intercellular junctions: rapid-freezing by jet propane. J. Cell Sci. 62: 223-236.

Treherne, J. E., and P. K. Schofield (1979) Ionic homeostasis of the brain microenvironment in insects. Trends Neurosci. 2: 227-230.

Treherne, J. E., and P. K. Schofield (1981) Mechanisms of ionic homeostasis in an insect CNS. J. Exp. Biol. 95: 61-73.

van Deurs, B., V. Dantzer, and J. Bresciani (1982) Gap junction pleiomorphism in the root system of the rhizocephalans (Arthropoda: Crustacea). Eur. J. Cell Biol. 27: 256-261.

Wood, R. L., and A. M. Kuda (1980) Formation of junctions in regenerating Hydra: septate junctions. J. Ultrastruct. Res. 70: 104117. 